OPEN ACCESS

Edited by:

Gen-Min Lin,

Hualien Armed Forces General

Hospital, Taiwan

Reviewed by:

Yuling Yu,

Guangdong Academy of Medical

Sciences, China

Palash Chandra Banik,

Bangladesh University of Health

Sciences, Bangladesh

${ }^{*}$ Correspondence:

Sufeng Yin

suan.me@163.com

Xuguang Gao

gxg56@tom.com

Shouling Wu

drwus/@163.com

tThese authors have contributed equally to this work

Specialty section:

This article was submitted to Cardiovascular Epidemiology and

Prevention,

a section of the journal

Frontiers in Cardiovascular Medicine

Received: 25 March 2021

Accepted: 07 June 2021

Published: 12 July 2021

Citation:

Yu Y, Dong Z, Li Y, Zhang J, Yin S,

Gao X, Wu S and Kailuan Study

Investigators (2021) The

Cardiovascular and Cerebrovascular

Health in North China From 2006 to

2011: Results From the Kailuan

Study.

Front. Cardiovasc. Med. 8:683416.

doi: $10.3389 / f c v m .2021 .683416$

\section{The Cardiovascular and} Cerebrovascular Health in North China From 2006 to 2011: Results From the KaiLuan Study

\author{
Yao Yu ${ }^{1+}$, Zhiyi Dong ${ }^{2+}$, Yongjie $\mathrm{Li}^{1}$, Jun Zhang ${ }^{1}$, Sufeng Yin ${ }^{3 *}$, Xuguang Gao ${ }^{1 *}$, \\ Shouling $W^{4 *}$ and KaiLuan Study Investigators
}

\begin{abstract}
${ }^{1}$ Department of Neurology, Peking University People's Hospital, Beijing, China, ${ }^{2}$ Department of Biomedical Engineering, Stony Brook University, Stony Brook, NY, United States, ${ }^{3}$ Department of Preventive Medicine, School of Public Health, North China University of Science and Technology, Tangshan, China, ${ }^{4}$ Department of Cardiology, Kailuan General Hospital, North China University of Science and Technology, Tangshan, China
\end{abstract}

Background: The American Heart Association (AHA) defined cardiovascular health in terms of four behaviors (smoking, diet, physical activity, body weight) and three factors (plasma glucose, cholesterol, blood pressure). By this definition, the prevalence of ideal cardiovascular health behaviors and factors is negatively correlated with all-cause mortality and risks of cardiovascular and cerebrovascular diseases and malignancy. We analyzed the trends in cardiovascular and cerebrovascular health behaviors and factors in the population of the KaiLuan study for 2006-2011, reported the results, and provided evidence for prevention.

Methods and Results: We calculated the prevalence of cardiovascular and cerebrovascular health behaviors and factors from KaiLuan data for 2006-2007, 2008-2009, and 2010-2011. The prevalence of ideal cardiovascular and cerebrovascular health behaviors and factors is low in the KaiLuan population.

Conclusions: The prevalence of ideal cardiovascular and cerebrovascular health behaviors and factors is low in the KaiLuan population.

Clinical Trial Registration: http://www.chictr.org/cn/proj/show.aspx?proj=1441, unique identifier: ChiCTR-TNC-11001489.

Keywords: epidemiology, cardiovascular and cerebrovascular disease risk factor, prevention, trends, Kailuan study

\section{INTRODUCTION}

The American Heart Association (AHA) defined four cardiovascular health behaviors (smoking, diet, physical activity, body weight) and three health factors (plasma glucose, cholesterol, blood pressure) based on epidemiologic data (1). By this definition, the prevalence of ideal cardiovascular health behaviors and factors is negatively correlated with all-cause mortality and risks of cardiovascular disease and malignancy (1-10). Recently, because of lifestyle improvements, the incidence of cardiovascular and cerebrovascular diseases has shown a downward trend $(11,12)$. 
Ideal cardiovascular and cerebrovascular health metrics are also protective against cerebrovascular disease (13-15). Zeng et al. reported their prevalence in the Chinese population (16, 17); such findings suggest that the prevalence of ideal AHA behaviors and factors is low among the Chinese population, and we speculate that this is one reason why the incidence of mortality from chronic non-communicable diseases has increased in China recently $(18,19)$.

The incidence of cardiovascular and cerebrovascular events in the Chinese population in the future will be determined by cardiovascular health behaviors and factors. We analyzed the trends among the population of the KaiLuan study for 2006-2011, reported the results, and provided evidence for the future.

\section{METHODS}

\section{Subjects}

The study was approved by the KaiLuan General Hospital Ethics Committee. The KaiLuan study began in July 2006 with a prospective cohort based on the KaiLuan community focusing on risk factors and interventions for cardiologic, cerebrovascular, and related diseases. The KaiLuan Group Co., Ltd. produces coal and chemical industrial products; it is located in the city of Tangshan in the center of the Bohai Sea Gulf region and has 150,000 serving and retired employees. The KaiLuan community is owned and managed by the KaiLuan Group and has 11 hospitals responsible for its healthcare (13). Employees undergo health examination funded by the KaiLuan Group every 2 years; data are now available for 2006-2007, 2008-2009, and2010-2011.

The inclusion criteria for this study were as follows: age $\geq 18$ years, cognitive ability sufficient to complete the questionnaire oneself, and provision of informed consent. The exclusion criteria were as follows: history of stroke or myocardial infarction, glomerular filtration rate $<30 \mathrm{ml} / \mathrm{min} / 1.73 \mathrm{~m}^{2}$, or data related to cardiovascular health behaviors and factors missing.

\section{Definition of Cardiovascular and Cerebrovascular Health Metrics}

The cardiovascular and cerebrovascular health behaviors and factors investigated in this study are those defined by the AHA (1). Because the questionnaire used in the KaiLuan study did not ask about vegetable intake and the China National Nutrition and Health Survey shows that only $18.4 \%$ of Chinese people had daily salt intake $<6 \mathrm{~g}$ in 2002 , salt preference was used as a surrogate for the diet metric of AHA. Because the amount of salt consumed was not measured precisely, salt preference was classified as "low," "medium," or "high," with low substituted for the ideal level of the metric of AHA (15). Cardiovascular and cerebrovascular health metrics as defined by the 2020 Strategic Impact Goals Committee of AHA and the KaiLuan study are displayed in Tables 1, 2. The histories of hypertension, diabetes mellitus, stroke, and myocardial infarction of the subjects were determined from the survey questionnaire.

\section{Survey Questionnaire and Anthropometric Measurements}

Details of these procedures have been published previously (13, 20-22).

\section{Statistics}

Statistical analyses were performed using SPSS for Windows v13.0 (SPSS Inc., Chicago, IL, USA). Continuous variables were described by the mean \pm standard deviation and categorical variables by percentages.

\section{RESULTS}

The numbers of employees who participated in the 2006-2007, 2008-2009, and 2010-2011 health examinations were 101,510, 101,133 , and 92,967 , respectively. The following numbers were excluded from our study: 10,126 from 2006 to $2007(2,556$ history of stroke, 1,316 history of myocardial infarction, 563 glomerular filtration rate $<30 \mathrm{ml} / \mathrm{min} / 1.73 \mathrm{~m}^{2}, 6,051$ incomplete data), 14,657 from 2008 to 2009 (2,417 history of stroke, 1,033 history of myocardial infarction, 287 glomerular filtration rate $<30 \mathrm{ml} / \mathrm{min} / 1.73 \mathrm{~m}^{2}, 11,506$ incomplete data), and 11,050 from 2010 to 2011 (2,362 history of stroke, 1,308 history of myocardial infarction, 170 glomerular filtration rate $<30$ $\mathrm{ml} / \mathrm{min} / 1.73 \mathrm{~m}^{2}, 7,681$ incomplete data). Ultimately, 91,384, 86,476 , and 81,917 subjects, respectively, were included in the study; $79.39 \%(72,552), 78.92 \%(68,245)$, and $78.54 \%(64,339)$ were male. Their average ages were $50.47 \pm 12.35,50.71 \pm 12.48$, and $51.32 \pm 12.95$ years.

The prevalence of cardiovascular and cerebrovascular health metrics categorized as poor, intermediate, or ideal for 2006-2007, 2008-2009, and 2010-2011 is displayed by sex in Tables 3, 4 .

In this study, 57,659 individuals participated in all three health examinations. We analyzed the data for these individuals only using the methods above and obtained similar results (Supplementary Tables 1, 2).

\section{DISCUSSION}

The cardiovascular and cerebrovascular health behaviors and factors in the KaiLuan population show two characteristics for 2006-2011. First, the prevalence of the ideal level of each metric is low; for salt preference and physical activity, it is $<20 \%$. In the USA, only the prevalence of ideal diet is $<1 \%$; the ideal levels of the other six metrics are $>35 \%$. Second, the prevalence of the poor level of each metric is high: up to $30 \%$ for poor blood pressure and around $10 \%$ for the other six. In the USA, with the exception of diet and physical activity, the poor level prevalence is about $10 \%$. If we had defined these two metrics according to the AHA, the prevalence of their ideal levels would be much lower and those of their poor levels much higher.

A high salt diet is a risk factor for cardiovascular diseases such as hypertension (23). In 2007, the World Health Organization (WHO) recommended a daily salt intake of $<5 \mathrm{~g}$ (24). The China National Nutrition and Health Survey showed that only $18 \%$ of the population consumed $<6 \mathrm{~g}$ of salt daily. The 
TABLE 1 | Definitions of cardiovascular health metrics from the 2020 Strategic Impact Goals Committee of the American Heart Association.

\begin{tabular}{|c|c|c|c|}
\hline \multirow[b]{2}{*}{ Metric } & \multirow[b]{2}{*}{ Poor } & Level of cardiovascular health & \multirow[b]{2}{*}{ Ideal } \\
\hline & & Intermediate & \\
\hline Smoking & Current smoker & Quit smoking <12 months ago & Never smoker or quit smoking $\geq 12$ months ago \\
\hline Diet $^{\mathrm{a}}$ & Diet score $=0 / 1$ & Diet score $=2 / 3$ & Diet score $=4 / 5$ \\
\hline Physical activity ${ }^{\mathrm{b}}$ & No physical activity & $\begin{array}{l}1-149 \mathrm{~min} / \text { week moderate intensity or } 1-74 \\
\mathrm{~min} / \text { week vigorous intensity or } 1-149 \\
\mathrm{~min} / \text { week moderate and vigorous }\end{array}$ & $\begin{array}{l}\geq 150 \mathrm{~min} / \text { week moderate intensity or } \geq 75 \\
\mathrm{~min} / \text { week vigorous intensity or } \geq 150 \mathrm{~min} / \text { week } \\
\text { moderate and vigorous }\end{array}$ \\
\hline Body weight & $\mathrm{BMI} \geq 30 \mathrm{~kg} / \mathrm{m}^{2}$ & BMl $25-29.9 \mathrm{~kg} / \mathrm{m}^{2}$ & $\mathrm{BMl}<25 \mathrm{~kg} / \mathrm{m}^{2}$ \\
\hline Fasting plasma glucose & $\geq 126 \mathrm{mg} / \mathrm{dl}$ & $100-125 \mathrm{mg} / \mathrm{dl}$ or treated to goal & $<100 \mathrm{mg} / \mathrm{dl}$ \\
\hline Total cholesterol & $\geq 240 \mathrm{mg} / \mathrm{dl}$ & 200-239 or treated to goal & $<200 \mathrm{mg} / \mathrm{dl}$ \\
\hline Blood pressure & $\mathrm{SBP} \geq 140 \mathrm{~mm} \mathrm{Hg}$ or $\mathrm{DBP} \geq 90 \mathrm{~mm} \mathrm{Hg}$ & $\begin{array}{l}\text { SBP } 120-139 \mathrm{~mm} \mathrm{Hg} \text { or DBP } 80-89 \mathrm{~mm} \mathrm{Hg} \text { or } \\
\text { treated to goal }\end{array}$ & $<120 /<80 \mathrm{~mm} \mathrm{Hg}$ \\
\hline
\end{tabular}

$B M I$, body mass index; SBP, systolic blood pressure; DBP, diastolic blood pressure.

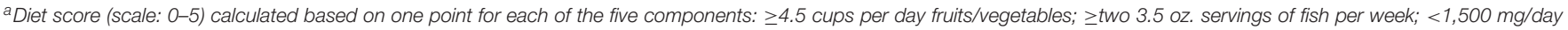
sodium; $\leq 450 \mathrm{kcal}$ (36 oz.) per week sweets/sugar-sweetened beverages; and $\geq$ three servings per day whole grains (1.1 g of fiber in $10 \mathrm{~g}$ of carbohydrate; $1 \mathrm{oz}$. equivalent servings).

${ }^{b}$ Leisure time physical activity.

TABLE 2 | Definitions of cardiovascular and cerebrovascular health metrics from the Kailuan study.

Level of cardiovascular health

\begin{tabular}{|c|c|c|c|}
\hline Metric & Poor & Intermediate & Ideal \\
\hline Smoking & Current smoker & Quit smoking $<12$ months ago & Never smoker or quit smoking $\geq 12$ months ago \\
\hline Salt preference & High & Medium & Low \\
\hline Physical activity & Inactive (none) & Moderately active & $\begin{array}{l}\text { Very active ( } \geq \text { three times/week and } \geq 30 \mathrm{~min} \\
\text { each time) }\end{array}$ \\
\hline Body weight & $\mathrm{BMI} \geq 30 \mathrm{~kg} / \mathrm{m}^{2}$ & BMI $25-29.9 \mathrm{~kg} / \mathrm{m}^{2}$ & $\mathrm{BMl}<25 \mathrm{~kg} / \mathrm{m}^{2}$ \\
\hline Fasting plasma glucose & $\geq 126 \mathrm{mg} / \mathrm{dl}$ & $100-125 \mathrm{mg} / \mathrm{dl}$ or treated to goal & $<100 \mathrm{mg} / \mathrm{dl}$ \\
\hline Total cholesterol & $\geq 240 \mathrm{mg} / \mathrm{dl}$ & 200-239 mg/dl or treated to goal & $<200$ mg/dl \\
\hline Blood pressure & $\mathrm{SBP} \geq 140 \mathrm{~mm} \mathrm{Hg}$ or $\mathrm{DBP} \geq 90 \mathrm{~mm} \mathrm{Hg}$ & $\begin{array}{l}\text { SBP } 120-139 \mathrm{~mm} \mathrm{Hg} \text { or DBP } 80-89 \mathrm{~mm} \mathrm{Hg} \text { or } \\
\text { treated to goal }\end{array}$ & $<120 /<80 \mathrm{~mm} \mathrm{Hg}$ \\
\hline
\end{tabular}

BMI, body mass index; SBP, systolic blood pressure; DBP, diastolic blood pressure.

prevalence of ideal salt preference is about $17 \%$ in 2011 . We must improve this situation and it is important for the prevention and control of cardiovascular and cerebrovascular diseases. Salt-sensitive hypertension accounts for $60 \%$ of the cases of hypertension in China (25), and a study has indicated that reducing salt consumption by $15 \%$, accompanied by tobacco control, will save 45 million lives at a cost of $<3$ yuan per person (US\$0.4) (26).

Smoking is related to many conditions and is a risk factor for cardiovascular disease $(27,28)$, the incidence of which declines with quitting smoking (29-31). For patients with cardiovascular disease, quitting smoking leads to a greater all-cause mortality reduction than controlling blood pressure, total cholesterol, and other risk factors, though its effect is less than that of aspirin (32). China is a major consumer of tobacco (33). The number of male smokers is up to 300 million, accounting for one-third of the total number worldwide. The annual economic burden due to smoking is $\sim$ US $\$ 350$ million (34). For men, the prevalence of poor smoking level was up to $45 \%$ in 2011. Further strict controls on tobacco should be established to achieve health goals (35).

In 2011 , the prevalence of physical inactivity is about $30 \%$. Physical activity is an important cardiovascular health behavior, improving not only blood pressure but also fasting plasma glucose, total cholesterol, and other health indicators $(36,37)$. There is a significant relationship between frequency of exercise and medical costs incurred (38). Weight gain and increased total cholesterol and fasting plasma glucose resulting from physical inactivity will weaken or even counteract the benefits from the improvement of other cardiovascular health metrics. In this era of readily available transportation, mechanization in the workplace, and television and the internet at home, how to improve the willingness of citizens to participate in physical exercise is a challenge that must be addressed.

In 2011, the prevalence of the ideal levels of total cholesterol and BMI is more than $50 \%$. The prevalence of poor levels of fasting plasma glucose is about $7 \%$. It will be necessary to increase 
TABLE 3 | Distribution (2006-2007, 2008-2009, and 2010-2011) of poor, intermediate, and ideal levels of cardiovascular health metrics for men (KaiLuan study).

\begin{tabular}{|c|c|c|c|}
\hline & 2006-2007 & 2008-2009 & 2010-2011 \\
\hline \multicolumn{4}{|l|}{ Smoking } \\
\hline Poor & 44.76 & 52.37 & 45.03 \\
\hline Intermediate & 5.80 & 5.5 & 5.26 \\
\hline Ideal & 49.44 & 42.13 & 49.71 \\
\hline \multicolumn{4}{|l|}{ Salt } \\
\hline Poor & 11.75 & 12.95 & 11.93 \\
\hline Intermediate & 79.18 & 73.59 & 70.36 \\
\hline Ideal & 9.07 & 13.46 & 17.71 \\
\hline \multicolumn{4}{|c|}{ Physical activity } \\
\hline Poor & 11.01 & 22.45 & 33.37 \\
\hline Intermediate & 76.04 & 61.61 & 54.17 \\
\hline Ideal & 12.94 & 15.94 & 12.47 \\
\hline \multicolumn{4}{|l|}{ Body weight } \\
\hline Poor & 8.47 & 7.83 & 8.31 \\
\hline Intermediate & 41.60 & 40.22 & 41.64 \\
\hline Ideal & 49.93 & 51.95 & 50.04 \\
\hline \multicolumn{4}{|l|}{ Glucose } \\
\hline Poor & 6.99 & 7.7 & 6.90 \\
\hline Intermediate & 22.86 & 25.99 & 26.79 \\
\hline Ideal & 70.15 & 66.31 & 66.31 \\
\hline \multicolumn{4}{|c|}{ Total cholesterol } \\
\hline Poor & 9.65 & 9.68 & 7.69 \\
\hline Intermediate & 26.56 & 25.6 & 23.00 \\
\hline Ideal & 63.79 & 64.72 & 69.31 \\
\hline \multicolumn{4}{|c|}{ Blood pressure } \\
\hline Poor & 38.83 & 40.89 & 37.17 \\
\hline Intermediate & 41.01 & 42.45 & 46.80 \\
\hline Ideal & 20.16 & 16.66 & 16.03 \\
\hline
\end{tabular}

publicity and improve education at both the individual and population levels to increase physical activity and halt this trend.

There is a linear relationship between blood pressure and the incidence of cardiovascular and cerebrovascular diseases, with the risk of these conditions increasing with rising blood pressure above $115 / 75 \mathrm{~mm} \mathrm{Hg}(39,40)$. Blood pressure is one of the most important risk factors for cardiovascular disease and its control is crucial (41-43). Early intervention for hypertension and its complications can reduce the high cost of treatment and improve quality of life caused by cardiovascular and cerebrovascular diseases and other chronic non-communicable conditions $(44,45)$. In 2011, the prevalence of poor levels of blood pressure is up to $40 \%$ in men. Measures should be taken to control the situation.

In 2013, the WHO issued a draft action plan for the prevention and control of non-communicable diseases in 2013-2020 and a draft comprehensive global monitoring framework and targets. It was determined that agencies of the WHO and the United Nations and other international partners will take action together to achieve goals of reducing the prevalence of smoking by $15 \%$ among people aged $\geq 15$ years, the average intake of salt/sodium by $30 \%$, and the prevalence of physical inactivity by $10 \%$;
TABLE 4 | Distribution (2006-2007, 2008-2009, and 2010-2011) of poor, intermediate, and ideal levels of cardiovascular and cerebrovascular health metrics for women (Kailuan study).

\begin{tabular}{|c|c|c|c|}
\hline & 2006-2007 & 2008-2009 & 2010-2011 \\
\hline \multicolumn{4}{|l|}{ Smoking } \\
\hline Poor & 1.81 & 1.54 & 1.09 \\
\hline Intermediate & 0.39 & 0.26 & 0.22 \\
\hline Ideal & 97.8 & 98.2 & 98.69 \\
\hline \multicolumn{4}{|l|}{ Salt } \\
\hline Poor & 6.67 & 8.35 & 6.88 \\
\hline Intermediate & 83.96 & 75.09 & 75.37 \\
\hline Ideal & 9.38 & 16.55 & 17.76 \\
\hline \multicolumn{4}{|c|}{ Physical activity } \\
\hline Poor & 4.80 & 17.6 & 30.83 \\
\hline Intermediate & 83.65 & 66.94 & 58.05 \\
\hline Ideal & 11.55 & 15.46 & 11.12 \\
\hline \multicolumn{4}{|l|}{ Body weight } \\
\hline Poor & 7.63 & 6.36 & 6.56 \\
\hline Intermediate & 30.49 & 29.05 & 29.54 \\
\hline Ideal & 61.88 & 64.59 & 63.90 \\
\hline \multicolumn{4}{|l|}{ Glucose } \\
\hline Poor & 5.86 & 5.62 & 5.19 \\
\hline Intermediate & 15.76 & 17.86 & 19.47 \\
\hline Ideal & 78.38 & 76.52 & 75.34 \\
\hline \multicolumn{4}{|c|}{ Total cholesterol } \\
\hline Poor & 9.44 & 8.48 & 8.42 \\
\hline Intermediate & 26.11 & 23.29 & 22.25 \\
\hline Ideal & 64.46 & 68.23 & 69.34 \\
\hline \multicolumn{4}{|c|}{ Blood pressure } \\
\hline Poor & 24.99 & 22.33 & 21.75 \\
\hline Intermediate & 37.04 & 35.13 & 40.17 \\
\hline Ideal & 37.96 & 42.55 & 38.09 \\
\hline
\end{tabular}

controlling the increase of diabetes and obesity; controlling or reducing the prevalence of high blood pressure by 25\%; and reducing the risk of early death from cardiovascular disease and other chronic non-communicable diseases by $25 \%$ by 2025 $(46,47)$. The Chinese government proposed a Health China 2020 strategy (35) with the goals of controlling the prevalence of smoking at $40 \%$ for men and $4 \%$ for women (aged $\geq 15$ years), reducing daily sodium intake to $8 \mathrm{~g}$, maintaining the prevalence of frequent participation in physical activity at $\geq 40 \%$ of the population (aged $\geq 8$ years), controlling the prevalence of overweight adults at 25\%, controlling the prevalence of high fasting plasma glucose with diabetes at $45 \%$, controlling the prevalence of hypertension at $30 \%$, and reducing mortality from cardiovascular disease by $30 \%$.

It should be noted that we have undertaken health education in 11,679 patients with hypertension among the study population who met certain criteria, measuring their blood pressure every 2 weeks and administering nitrendipine, hydrochlorothiazide, captopril, and spironolactone antihypertensive drugs without charge since April 2009. These interventions may have influenced the results of the present study; the real situation may thus be worse. 


\section{DATA AVAILABILITY STATEMENT}

The raw data supporting the conclusions of this article will be made available by the authors, without undue reservation.

\section{AUTHOR CONTRIBUTIONS}

All authors listed have made a substantial, direct and intellectual contribution to the work, and approved it for publication.

\section{REFERENCES}

1. Lloyd-Jones DM, Hong YL, Labarthe D, Mozaffarian D, Appel LJ, Van Horn L, et al. Defining and setting national goals for cardiovascular health promotion and disease reduction: the American heart association's strategic impact goal through 2020 and beyond. Circulation. (2010) 121:586613. doi: 10.1161/CIRCULATIONAHA.109.192703

2. Christina MS, Ning H, Allen NB, Carnethon MR, Chiuve SE, Greenlund KJ, et al. Status of cardiovascular health in US adults: prevalence estimates from the National health and nutrition examination surveys (NHANES) 2003-2008. Circulation. (2012) 125:45-56. doi: 10.1161/CIRCULATIONAHA.111.035733

3. Laitinen TT, Pahkala K, Magnussen CG, Viikari JS, Oikonen M, Taittonen L, et al. Ideal cardiovascular health in childhood and cardiometabolic outcomes in adulthood: the cardiovascular risk in young finns study. Circulation. (2012) 125:1971-8. doi: 10.1161/CIRCULATIONAHA.111.073585

4. Folsom AR, Yatsuya $H$, Nettleton JA, Lutsey PL, Cushman M, Rosamond WD, et al. Community prevalence of ideal cardiovascular health, by the American heart association definition, and relationship with cardiovascular disease incidence. J Am Coll Cardiol. (2011). 57:1690-6. doi: 10.1016/j.jacc.2010.11.041

5. Giampaoli S, Palmieri L, Panico S, Vanuzzo D, Ferrario M, Chiodini P, et al. Favorable cardiovascular risk profile (low risk) and 10-year stroke incidence in women and men: findings from 12 Italian population samples. Am J Epidemiol. (2006) 163:893-902. doi: 10.1093/aje/kwj110

6. Song YM, Sung J, Smith GD, Ebrahim S. Original contributions: body mass index and ischemic and hemorrhagic stroke: a prospective study in Korean men. Stroke. (2004) 35:831-6. doi: 10.1161/01.STR.0000119386.22691.1C

7. Zhang XF, Attia J, D'Este C, Yu XH. Original contributions: prevalence and magnitude of classical risk factors for stroke in a cohort of 5092 Chinese steelworkers over 13.5 years of follow-up. Stroke. (2004) 35:10526. doi: 10.1161/01.STR.0000125305.12859.ff

8. Koren-Morag N, Tanne D, Graff E, Goldbourt U. Low and high-density lipoprotein cholesterol and ischemic cerebrovascular disease. Arch Intern Med. (2002) 162:993-9. doi: 10.1001/archinte.162.9.993

9. Tanne D, Koren-Morag N, Goldbourt U. Fasting plasma glucose and risk of incident ischemic stroke or transient ischemic attacks: a prospective cohort study. Stroke. (2004) 35:2351-5. doi: 10.1161/01.STR.0000140738.94047.55

10. Rasmussen-Torvik LJ, Shay CM, Abramson JG, Friedrich CA, Nettleton JA, Prizment AE, et al. Ideal cardiovascular health is inversely associated with incident cancer: the atherosclerosis risk in communities study. Circulation. (2013) 127:1270-5. doi: 10.1161/CIRCULATIONAHA.112.001183

11. Ford ES, Capewell S. Proportion of the decline in cardiovascular mortality disease due to prevention versus treatment: public health versus clinical care. Annu Rev Public Health. (2011) 32:5-22. doi: 10.1146/annurev-publhealth-031210-101211

12. Huffman MD, Capewell S, Ning H, Shay CM, Ford ES, LloydJones DM. Cardiovascular health behavior and health factor changes (1988-2008) and projections to 2020: results from the national health and nutrition examination surveys. Circulation. (2012). 125:2595-2602. doi: 10.1161/CIRCULATIONAHA.111.070722

13. Wu S, Huang Z, Yang X, Zhou Y, Wang A, Chen L. Prevalence of ideal cardiovascular health and its relationship with the 4-year cardiovascular

\section{ACKNOWLEDGMENTS}

We thank the staff and participants of the KaiLuan study for their important contributions.

\section{SUPPLEMENTARY MATERIAL}

The Supplementary Material for this article can be found online at: https://www.frontiersin.org/articles/10.3389/fcvm. 2021.683416/full\#supplementary-material events in a northern Chinese industrial city. Circ Cardiovasc Qual Outcomes. (2012). 5:487-93. doi: 10.1161/CIRCOUTCOMES.111.963694

14. Zhang Q, Zhang S, Wang C, Gao X, Zhou Y, Zhou H, et al. Ideal cardiovascular health metrics on the prevalence of asymptomatic intracranial artery stenosis: a cross-sectional study. PLoS ONE. (2013) 8:e58923. doi: 10.1371/journal.pone.0058923

15. Zhang Q, Zhou Y, Gao X, Wang C, Zhang S, Wang A, et al. Ideal cardiovascular health metrics and the risks of ischemic and intracerebral hemorrhagic stroke. Stroke. (2013) 44:24516. doi: 10.1161/STROKEAHA.113.678839

16. Zeng Q, Dong SY, Song ZY, Zheng YS, Wu HY, Mao LN. Ideal cardiovascular health in Chinese urban population. Int J Cardiol. (2013) 167:23117. doi: $10.1016 /$ j.ijcard.2012.06.022

17. Wu HY, Sun ZH, Cao DP, Wu LX, Zeng Q. Cardiovascular health status in Chinese adults in urban areas: analysis of the Chinese health examination database 2010. Int J Cardiol. (2013) 168:760-4. doi: 10.1016/j.ijcard.2012.09.235

18. Yang G, Kong L, Zhao W, Zhai Y, Chen LC, Koplan JP. Emergence of chronic non-communicable diseases in China. Lancet. (2008) 372:1697705. doi: 10.1016/S0140-6736(08)61366-5

19. Moran A, Zhao D, Gu D, Coxson P, Chen CS, Cheng J, et al. The future impact of population growth and aging on coronary heart disease in China: projections from the coronary heart disease policy model-China. BMC Public Health. (2008) 8:394. doi: 10.1186/1471-2458-8-394

20. Wu S, Li Y, Jin C, Yang P, Li D, Li H, et al. Intra-individual variability of highsensitivity C-reactive protein in Chinese general population. Int J Cardiol. (2012) 157:75-9. doi: 10.1016/j.ijcard.2010.12.019

21. Wang F, Wu SL, Song Y, Tang X, Marshall R, Liang M, et al. Waist circumference, body mass index and waist to hip ratio for prediction of the metabolic syndrome in Chinese. Nutr Metab Cardiovasc Dis. (2009) 19:542-7. doi: 10.1016/j.numecd.2008.11.006

22. Jia ZX, Zhou Y, Liu XR, Wang YL, Zhao XQ, Wang YJ, et al. Comparison of different anthropometric measures as predictors of diabetes incidence in a Chinese population. Diabetes Res Clin Pract. (2011) 92:26571. doi: 10.1016/j.diabres.2011.01.021

23. Karppanen H, Mervalla E. Sodium intake and hypertension. Prog Cardiovasc Dis. (2006) 49:59-75. doi: 10.1016/j.pcad.2006.07.001

24. World Health Organization. Reducing Salt Intake in Populations. Geneva: WHO (2007).

25. Mu J, Zheng S, Lian Q, Liu F, Liu Z. Evolution of blood pressure from adolescents to youth in salt sensitivies: a 18-year follow-up study in Hanzhong children cohort. Nutr J. (2012). 11:70. doi: 10.1186/1475-2891-11-70

26. Asaria P, Chisholm D, Mathers C, Ezzati M, Beaqlehole R. Chronic disease prevention: health effects and financial costs of strategies to reduce salt intake and control tobacco use. Lancet. (2007) 370:204453. doi: 10.1016/S0140-6736(07)61698-5

27. Judith M, Michael E. The Tobacco Control Atlas. Geneva: WHO (2002). p. $25-7$.

28. Teo KK, Ounpuu S, Hawken S, Valentin V, Hunt D, Diaz R, et al. Tobacco use and risk of myocardial infarction in 52 countries in the INTERHEART study: a case-control study. Lancet. (2006) 368:64758. doi: 10.1016/S0140-6736(06)69249-0 
29. Bartecchi C, Alsever RN, Nevin-Woods C, Thomas WM, Estacio RO, Bartelson BB, et al. Reduction in the incidence of acute myocardial infarction associated with a citywide smoking ordinance. Circulation. (2006) 114:14906. doi: 10.1161/CIRCULATIONAHA.106.615245

30. Cesaroni G, Forastiere F, Agabiti N, Valente P, Zuccaro P, Perucci CA. Effect of the Italian smoking ban on population rates of acute coronary events. Circulation. (2008) 117:11838. doi: 10.1161/CIRCULATIONAHA.107.729889

31. Glantz SA. Meta-analysis of the effects of smoke free laws on acute myocardial infarction: an update. Prev Med. (2008) 47:452-3. doi: 10.1016/j.ypmed.2008.06.007

32. Dinno A, Glantz S. Clean indoor air laws immediately reduce heart attacks. Prev Med. (2007) 45:9-11. doi: 10.1016/j.ypmed.2007.03.013

33. Rice VH, Stead L. Nursing intervention and smoking cessation: meta-analysis update. Heart Lung. (2006) 35:147-63. doi: 10.1016/j.hrtlng.2006.01.001

34. WHO. Building Blocks for Tobacco Control: A Handbook. Geneva: WHO (2002). p. 3-6.

35. The Committee of Healthy China 2020. Strategic Research Report. Healthy China 2020 Strategic Research Report. China. People's Medical Publishing House (2020).

36. Kokkinos P, Pittaras A, Manolis A, Panagiotakos D, Narayan P, Manjoros D, et al. Exercise capacity and 24-h blood pressure in prehypertensive men and women. Am J Hypertens. (2006) 19:251-8. doi: 10.1016/j.amjhyper.2005.07.021

37. Slentz CA, Duscha BD, Johnson JL, Ketchum K, Aiken LB, Samsa GP, et al. Effects of the amount of exercise on body weight, body composition, and measures of central obesity: STRRIDE-a randomized controlled study. Arch Intern Med. (2004) 164:31-9. doi: 10.1001/archinte.164.1.31

38. Wang F, Mcdonald T, Reffitt B, Edington DW. BMI, physical activity, and health care utilization costs among medicare retirees. Obes Res. (2005) 13:1450-7. doi: 10.1038/oby.2005.175

39. Lawes CM, Rodgers A, Bennett DA, Parag V, Suh I, Ueshima H, et al. Blood pressure and cardiovascular diseases in the Asia-Pacific region. J Hypertens. (2003). 21:707-16. doi: 10.1097/00004872-200304000-00013

40. Lewington S, Clarke R, Qizilbash N, Peto R, Collins R, Prospective Studies Collaboration. Age-specific relevance of usual blood pressure to vascular mortality: a meta-analysis of individual data for one million adults in 61 prospective studies. Lancet. (2002) 360:1903-13. doi: 10.1016/S0140-6736(02)11911-8
41. Hunt KJ, Resendez RG, Williams K, Haffner SM, Stern MP, San Antonio Heart Study. National cholesterol education program versus World health organization metabolic syndrome in relation to all-cause and cardiovascular mortality in the San Antonio heart study. Circulation. (2004) 10:12517. doi: 10.1161/01.CIR.0000140762.04598.F9

42. Lawlor DA, Smith GD, Ebrahim S. Does the new international diabetes federation definition of the metabolic syndrome predict CHD any more strongly than older definitions? Findings from the British women's heart and health study. Diabetologia. (2006) 1:41-8. doi: 10.1007/s00125-0050040-3

43. McNeill AM, Rosamond WD, Girman CJ, Golden SH, Schmidt MI, East HE, et al. The metabolic syndrome and 11-year risk of incident cardiovascular disease in the atherosclerosis risk in communities study. Diabetes Care. (2005) 2:385-90. doi: 10.2337/diacare.28.2.385

44. Chobanian AV, Bakris GL, Black HR, Cushman WC, Green LA, Izzo JL Jr, et al. The seventh report of the joint national committee on prevention, detection, evaluation and treatment of high blood pressure: the JNC 7 report. JAMA. (2003) 289:2560-72. doi: 10.1161/01.HYP.0000107251.49515.c2

45. Krousel-Wood MA, Muntner P, He J, Whelton PK. Primary prevent ion of essential hypertension. Med Clin North Am. (2004) 88:2238. doi: 10.1016/S0025-7125(03)00126-3

46. Draft Comprehensive Global Monitoring Framework and Targets for the Prevention and Control of Noncommunicable Diseases (A66/8). Available online at: https://apps.who.int/iris/handle/10665/105633

47. Draft Action Plan for the Prevention and Control of Noncommunicable Diseases 2013-2020 (A66/9). Available online at: https://apps.who.int/iris/ handle/10665/78618

Conflict of Interest: The authors declare that the research was conducted in the absence of any commercial or financial relationships that could be construed as a potential conflict of interest.

Copyright (C) 2021 Yu, Dong, Li, Zhang, Yin, Gao, Wu and KaiLuan Study Investigators. This is an open-access article distributed under the terms of the Creative Commons Attribution License (CC BY). The use, distribution or reproduction in other forums is permitted, provided the original author(s) and the copyright owner(s) are credited and that the original publication in this journal is cited, in accordance with accepted academic practice. No use, distribution or reproduction is permitted which does not comply with these terms. 